\title{
Serum sodium alterations in SARS CoV-2 (COVID-19) infection: impact on patient outcome
}

\author{
Andrea Berni', Danilo Malandrino², Giovanni Corona³, Mario Maggi4,5, Gabriele Parenti ${ }^{4,6}$, Benedetta Fibbi4,6, \\ Loredana Poggesi ${ }^{1,2}$, Alessandro Bartoloni ${ }^{2,7}$, Federico Lavorini ${ }^{2,8}$, Andrea Fanelli9, Giulia Scocchera9, \\ Carlo Nozzoli' ${ }^{10}$, Adriano Peris ${ }^{11}$, Filippo Pieralli12, Riccardo Pini2,13, Andrea Ungar2,14 and Alessandro Peri",5,6
}

${ }^{1}$ Internal Medicine Unit 3, Careggi University Hospital, Florence, Italy, ${ }^{2}$ Department of Experimental and Clinical Medicine, University of Florence, Florence, Italy, ${ }^{3}$ Endocrinology Unit, Medical Department, Azienda Usl Bologna Maggiore-Bellaria Hospital, Bologna, Italy, ${ }^{4}$ Endocrinology Unit, Careggi University Hospital, Florence, Italy, ${ }^{5}$ Department of Experimental and Clinical Biomedical Sciences 'Mario Serio', University of Florence, Florence, Italy, ' ${ }^{6}$ ituitary Diseases and Sodium Alterations Unit, ${ }^{7}$ Infectious and Tropical Diseases Unit, ${ }^{8}$ Pneumology and Thoraco Pulmonary Pathophysiology Unit, ${ }^{9}$ Internal Medicine Unit $2,{ }^{10}$ Internal Medicine Unit 1 , ${ }^{11}$ Intensive Care Unit and Regional ECMO Referral Center, ${ }^{12} \mathrm{High}$ Intensity Internal Medicine Unit, Careggi University Hospital, Florence, Italy, ${ }^{13}$ Department of Internal and Emergency Medicine, Careggi Hospital, Florence, Italy, and ${ }^{14}$ Geriatric-UTIG Unit, Careggi University Hospital, Florence, Italy

Correspondence should be addressed to A Peri Email alessandro.peri@unifi.it

\begin{abstract}
Objective: Hyponatremia is the most common electrolyte disorder in hospitalized patients and occurs in about $30 \%$ of patients with pneumonia. Hyponatremia has been associated with a worse outcome in several pathologic conditions The main objective of this study was to determine whether serum sodium alterations may be independent predictors of the outcome of hospitalized COVID-19 patients.

Design and methods: In this observational study, data from 441 laboratory-confirmed COVID-19 patients admitted to a University Hospital were collected. After excluding 61 patients (no serum sodium at admission available, saline solution infusion before sodium assessment, transfer from another hospital), data from 380 patients were analyzed. Results: 274 (72.1\%) patients had normonatremia at admission, 87 (22.9\%) patients had hyponatremia and 19 (5\%) patients had hypernatremia. We found an inverse correlation between serum sodium and IL-6, whereas a direct correlation between serum sodium and $\mathrm{PaO}_{2} / \mathrm{FiO}_{2}$ ratio was observed. Patients with hyponatremia had a higher prevalence of non-invasive ventilation and ICU transfer than those with normonatremia or hypernatremia. Hyponatremia was an independent predictor of in-hospital mortality (2.7-fold increase vs normonatremia) and each $\mathrm{mEq} / \mathrm{L}$ of serum sodium reduction was associated with a $14.4 \%$ increased risk of death.

Conclusions: These results suggest that serum sodium at admission may be considered as an early prognostic marker of disease severity in hospitalized COVID-19 patients.
\end{abstract}

\section{Introduction}

Hyponatremia, defineed as a serum sodium concentration $\left[\mathrm{Na}^{+}\right]<135 \mathrm{mEq} / \mathrm{L}$, is the most common electrolyte disorder in hospitalized patients (up to $30 \%)(1,2)$. The syndrome of inappropriate antidiuresis (SIAD) is the (c) 2021 European Society of Endocrinology Printed in Great Britain cause of hyponatremia in $40-50 \%$ of cases. However, the prevalence may be even higher in some pathological conditions, including, for instance, pneumonia, subarachnoid hemorrhage and traumatic brain injury (3). 
Noteworthy, infectious diseases and inflammatory conditions are effective triggers for non-osmotic induction of vasopressin secretion. In these situations, vasopressin secretion is mainly due to interleukin-6 (IL-6), which is released by monocytes and macrophages. IL- 6 can cross the blood-brain barrier and activates the circumventricular organs by binding to IL-6 receptors. This, in turn, induces vasopressin release by the supraoptic (SON) and the paraventricular nuclei (PVN) (4). In addition, IL-6 can directly induce vasopressin secretion by binding to IL-6 receptors expressed by the cells of the SON and the PVN (5). Therefore, IL-6 appears to play an important role in the pathogenesis of hyponatremia secondary to SIAD.

The COVID-19 infection is caused by the novel severe acute respiratory syndrome coronavirus 2 (SARS CoV-2). It originated in Wuhan (China) and it spread throughout the world with more than 62000000 affected patients by the end of November 2020 (COVID-19 Dashboard by the Center for System Science and Engineering (CSSE) at John Hopkins University (6). In its severe form, COVID-19 infection can cause interstitial pneumonia, multiple organ failure and death. More than 1400000 patients died because of COVID-19 infection by the end of November 2020.

Hyponatremia occurs in about $30 \%$ of patients with pneumonia (7) and it has been previously reported in $30-60 \%$ of SARS CoV-1 patients $(8,9,10)$. The prevalence of hyponatremia in COVID-19 patients has not been clearly defined, so far $(11,12)$. Analyses from series of patients in China reported a median serum $\left[\mathrm{Na}^{+}\right]$of 138 $\mathrm{mEq} / \mathrm{L}$ (13). However, natremia was significantly lower in patients with pulmonary involvement (14). Although SIAD appears in principle as the main determinant of hyponatremia in COVID-19 infection, other etiologies may be present. Hypovolemic hyponatremia may occur, for instance, as a consequence of diuretic therapy to treat pulmonary edema (11).

It is known that hyponatremia, even when mild, is associated with a worse outcome and an increased risk of death in different pathological conditions, including pneumonia (15), heart failure (16), acute myocardial infarction (17), cirrhosis (18), cancer $(19,20)$, elderly patients (21), and intensive care patients (22). These data have been confirmed by an extensive meta-analysis, which included 82 publications for a total of more than 850000 patients (23). Noteworthy, we have recently demonstrated that human cancer cell lines cultured in reduced extracellular $\left[\mathrm{Na}^{+}\right]$show a significant increase in their proliferation rate and invasive potential (24).

In SARS CoV-1 patients hyponatremia was associated with a worse outcome (ICU transfer, death) (9). As per
SARS CoV-2 patients, early observations reported that hyponatremia was associated with progression to a more severe disease $(14,25,26)$.

Interestingly, an hyperinflammation syndrome characterized by a massive release of cytokines may contribute to a fatal outcome in SARS CoV-2 infection, determining multiple organ failure (27). IL-6 appears to be one of the most important cytokines involved in COVID-19-induced pathology. Based on these data, tocilizumab, a humanized monoclonal antibody against the IL-6 receptor, has demonstrated clinical efficacy in the treatment of seriously ill patients (28). Interestingly, SIAD resolution after treatment with tocilizumab in a 6-years old girl with juvenile idiopathic arthritis has been reported (29). A subgroup of patients from our previous study, who had abnormal IL-6 levels, hyponatremia and rapid deterioration of respiratory function, received tocilizumab infusion and serum $\left[\mathrm{Na}^{+}\right]$normalization was observed (14).

In order to evaluate the clinical impact of serum $\left[\mathrm{Na}^{+}\right]$alterations and their correlation with IL-6 levels, we retrospectively evaluated data from all COVID-19 patients admitted to the Units (Internal Medicine, Infectious Diseases, Respiratory Diseases, Intensive Care) at the Careggi University Hospital in Florence that had been transformed into COVID-19 Units during the first wave of the pandemic in Spring 2020.

\section{Subjects and methods}

\section{Patients}

This observational study named 'Natremia, syndrome of inappropriate antidiuresis and pro-inflammatory cytokines' was revised and approved by the Ethical Committee of the Careggi University Hospital. Data from 441 laboratory-confirmed COVID-19 patients admitted from February 28 to May 28, 2020, at Internal Medicine, Infective Disease, Respiratory Disease and Intensive Care Units of the Careggi University Hospital in Florence, Italy, completely transformed into COVID-19 Units were examined. All the biochemistry measurements were performed at the central lab of the Careggi University Hospital. Of the 441 patients, those for whom serum $\left[\mathrm{Na}^{+}\right]$and/or hemogasanalysis were not available $(n=39)$, or those who were transferred from other hospitals and/or had received an infusion of saline solution $(n=22)$ were excluded from the analysis, which finally included 380 patients. 


\section{Statistical analysis}

Data were expressed as mean \pm S.D. when normally distributed, and as median (quartiles) for parameters with non-normal distribution, unless otherwise specified. Serum $\left[\mathrm{Na}^{+}\right]$was adjusted for serum glucose concentration by the formula: serum $\left[\mathrm{Na}^{+}\right](\mathrm{mEq} / \mathrm{L})+0.016 \times($ serum [glucose] $(\mathrm{mg} / \mathrm{dL})-100)$. We compared age, gender, total days of hospitalization, and serum $\left[\mathrm{Na}^{+}\right], \mathrm{PaO}_{2} / \mathrm{FiO}_{2}$ $(\mathrm{P} / \mathrm{F})$ ratio and IL-6 level at admission. For those with low $\mathrm{PaCO}_{2}$ (i.e. $<35 \mathrm{mmHg}$ ), $\mathrm{PaO}_{2}$ was corrected by the formula: $\mathrm{PaCO}_{2} \times 1.66+\mathrm{PaO}_{2}-66.4$.

In order to verify the possible relationship between serum $\left(\mathrm{Na}^{+}\right)$, IL-6 levels and $\mathrm{P} / \mathrm{F}$ ratio, we applied the fitting model analysis. Kaplan-Meier analysis of survival was performed with the definition of hazard ratios (HR) and 95\% confidence intervals, and a stepwise Cox regression was carried out for multivariate analysis adjusting all data for age and sex. All analyses were carried out with SPSS 22.0.1 statistical package and a $P<0.05$ was considered statistically significant.

\section{Results}

\section{Serum [Na ${ }^{+}$, IL-6 and P/F ratio}

The patients $(n=380)$, which were finally included in the study, were divided into three groups according to serum $\left[\mathrm{Na}^{+}\right]$at admission: patients with low serum $\left[\mathrm{Na}^{+}\right]$ (i.e. $<135 \mathrm{mEq} / \mathrm{L}$ ) (hypoNa group, $n=87,22.9 \%$ ), patients with high serum $\left[\mathrm{Na}^{+}\right]$(i.e. $>145 \mathrm{mEq} / \mathrm{L}$ ) (hyperNa group, $n=19,5 \%)$ and patients with normal serum $\left[\mathrm{Na}^{+}\right]$ (i.e. $135-145 \mathrm{mEq} / \mathrm{L}$ ) (normoNa group, $n=274,72.1 \%$ ). The distribution in the three groups was defined after correcting serum $\left[\mathrm{Na}^{+}\right]$for serum glucose. In particular, 10 patients were relocated from the hypoNa group into the normoNa group, whereas 1 patient was relocated from the normoNa to the hyperNa group after correction.

In the hypoNa group, the lowest serum $\left[\mathrm{Na}^{+}\right]$was 116 $\mathrm{mEq} / \mathrm{L}$ (range: 116-134 $\mathrm{mEq} / \mathrm{L}$ ). In the hyperNa group, the highest serum $\left[\mathrm{Na}^{+}\right]$was $170 \mathrm{mEq} / \mathrm{L}$ (range: $146-$ $170 \mathrm{mEq} / \mathrm{L}$ ). HyperNa patients were older compared to normoNa and hypoNa patients (Table 1).

In order to identify acute hypoxemic respiratory failure, we analyzed the ratio of the partial pressure of oxygen in arterial blood $\left(\mathrm{PaO}_{2}\right)$ to the inspired oxygen fraction $\left(\mathrm{FiO}_{2}\right)$, known as $\mathrm{P} / \mathrm{F}$. This is a widely used index of pulmonary gas exchange function, which allows to classify patients' respiratory impairment in defining acute lung injury $(\mathrm{P} / \mathrm{F} \leq 300 \mathrm{mmHg})$ and adult respiratory distress syndrome $(\mathrm{P} / \mathrm{F} \leq 200 \mathrm{mmHg}$ ) (30). HypoNa patients showed lower $\mathrm{P} / \mathrm{F}$ ratio values compared to normoNa patients and higher IL-6 levels compared to normoNa and hyperNa patients. Males and females were equally distributed within the three groups and the mean duration of hospitalization was similar. Serum creatinine and blood urea nitrogen (BUN) are also reported in Table 1. Of the 87 hypoNa patients, values of serum creatinine above the upper limit of normal were found in 20 cases. BUN was available for 28 hypoNa patients and in 7 of

Table 1 Demographic and clinical characteristics of the patients.

\begin{tabular}{l}
\hline \\
\hline Age (years) \\
Males, $n(\%)$ \\
Hospitalization (days) \\
Serum $\left[\mathrm{Na}^{+}\right]$(mEq/L) \\
Serum glucose (mg/dL) \\
Serum creatinine $(\mathrm{mg} / \mathrm{dL})$ \\
Serum creatinine > 1.2 mg/dL, $n$ (\%) \\
BUN (mg/dL) \\
$n$ \\
BUN > 23.4 mg/dL, $n(\%)$ \\
BUN/creatinine \\
$n$ \\
BUN/creatinine > 20, $n(\%)$ \\
P/F (mmHg) \\
IL-6 (pg/mL) \\
NIV, $n(\%)$ \\
ICU transfer, $n(\%)$
\end{tabular}

\begin{tabular}{c}
\hline Hyponatremia, $(n=87)$ \\
\hline $69.5 \pm 12.8$ \\
$59(68)$ \\
$19.6 \pm 16.0$ \\
$132.0 \pm 2.9^{* * *,+\dagger}$ \\
$121.8 \pm 43.3$ \\
$1.0(0.8-1.2)$ \\
$20(23)$ \\
$18.7(14.0-25.7)$ \\
28 \\
$7(25)^{\ddagger}$ \\
$16.1(14.2-20.2)$ \\
28 \\
$7(25)$ \\
$250.2 \pm 87.0^{*}$ \\
$20.5(13.5-44.1)^{*, \ddagger}$ \\
$34(39)^{\ddagger, * \star}$ \\
$30(34)^{\ddagger, * \star}$
\end{tabular}

\begin{tabular}{c} 
Normonatremia, $(n=274)$ \\
\hline $65.9 \pm 16.5$ \\
$167(61)$ \\
$16.0 \pm 13.5$ \\
$139.0 \pm 2.4$ \\
$127.7 \pm 49.0$ \\
$0.9(0.8-1.1)$ \\
$56(20)$ \\
$18.7(14.0-26.6)$ \\
82 \\
$21(26)^{\ddagger}$ \\
$18.0(15.1-21.9)$ \\
82 \\
$29(35)$ \\
$291.1 \pm 84.1$ \\
$9.5(5.1-22.3)$ \\
$62(22)^{\ddagger}$ \\
$59(22)^{\ddagger}$
\end{tabular}

\begin{tabular}{c}
\hline Hypernatremia, $(n=19)$ \\
\hline $82.2 \pm 13.1^{\dagger, \star}$ \\
$8(42)$ \\
$19.0 \pm 11.1$ \\
$154.1 \pm 7.8^{\star \star \star}$ \\
$119.4 \pm 52.5$ \\
$1.1(0.9-1.6)$ \\
$8(42)$ \\
$51.4(18.7-56.1)$ \\
11 \\
$8(73)$ \\
$20.6(17.8-27.1)$ \\
11 \\
$6(55)$ \\
$268.4 \pm 100$ \\
$7.1(3.6-18.3)$ \\
$1(5)$ \\
$1(5)$
\end{tabular}

\begin{tabular}{c}
\hline P value \\
\hline$<0.0001$ \\
0.104 \\
0.090 \\
$<0.0001$ \\
0.504 \\
0.784 \\
0.086 \\
0.768 \\
\\
0.005 \\
0.086 \\
\\
0.213 \\
0.001 \\
$<0.0001$ \\
0.001 \\
0.007 \\
\hline
\end{tabular}

Serum creatinine normal values: $0.7-1.2 \mathrm{mg} / \mathrm{dL} ; \mathrm{BUN}$ normal values: $4.7-23.4 \mathrm{mg} / \mathrm{dL}$.

${ }^{\dagger} P<0.001$ vs hyponatremia; ${ }^{*} P<0.001$ vs normonatremia; ${ }^{\ddagger} P<0.05$ vs hypernatremia; $* \star P<0.05$ vs normonatremia; $* \star \star * P<0.0001$ vs normonatremia; ${ }^{+\dagger} P<0.0001$ vs hypernatremia. 


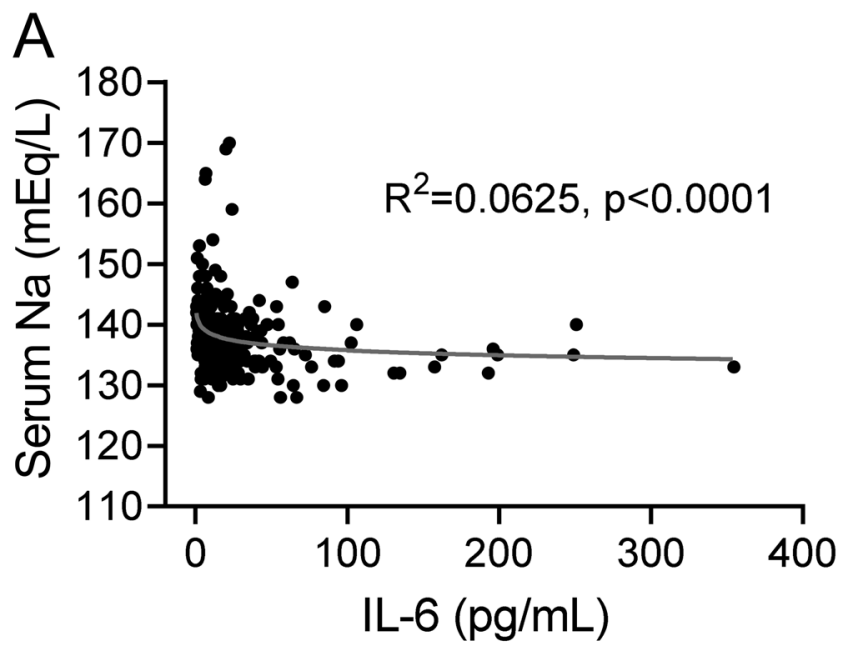

them values above the upper limit of normal occurred. In these patients, a BUN/creatinine ratio $>20$, which suggests a reduced extracellular fluid (ECF) volume, was also found (Table 1).

When the whole population was considered, a tight association among serum $\left[\mathrm{Na}^{+}\right]$, IL- 6 and P/F ratio was observed. Figure 1 shows the best-fitting model for variation in serum $\left[\mathrm{Na}^{+}\right]$as a function of IL-6 levels (Fig. 1A) and $\mathrm{P} / \mathrm{F}$ ratio (Fig. $1 \mathrm{~B}$ ). In particular, serum $\left[\mathrm{Na}^{+}\right]$was inversely correlated with IL-6 levels, whereas a direct correlation was observed between serum $\left[\mathrm{Na}^{+}\right]$and $\mathrm{P} / \mathrm{F}$ ratio. Figure $1 \mathrm{C}$ shows the best-fitting model for $\mathrm{P} / \mathrm{F}$ ratio as a function of IL- 6 levels variation and indicates that IL-6 levels were inversely correlated with the P/F ratio.
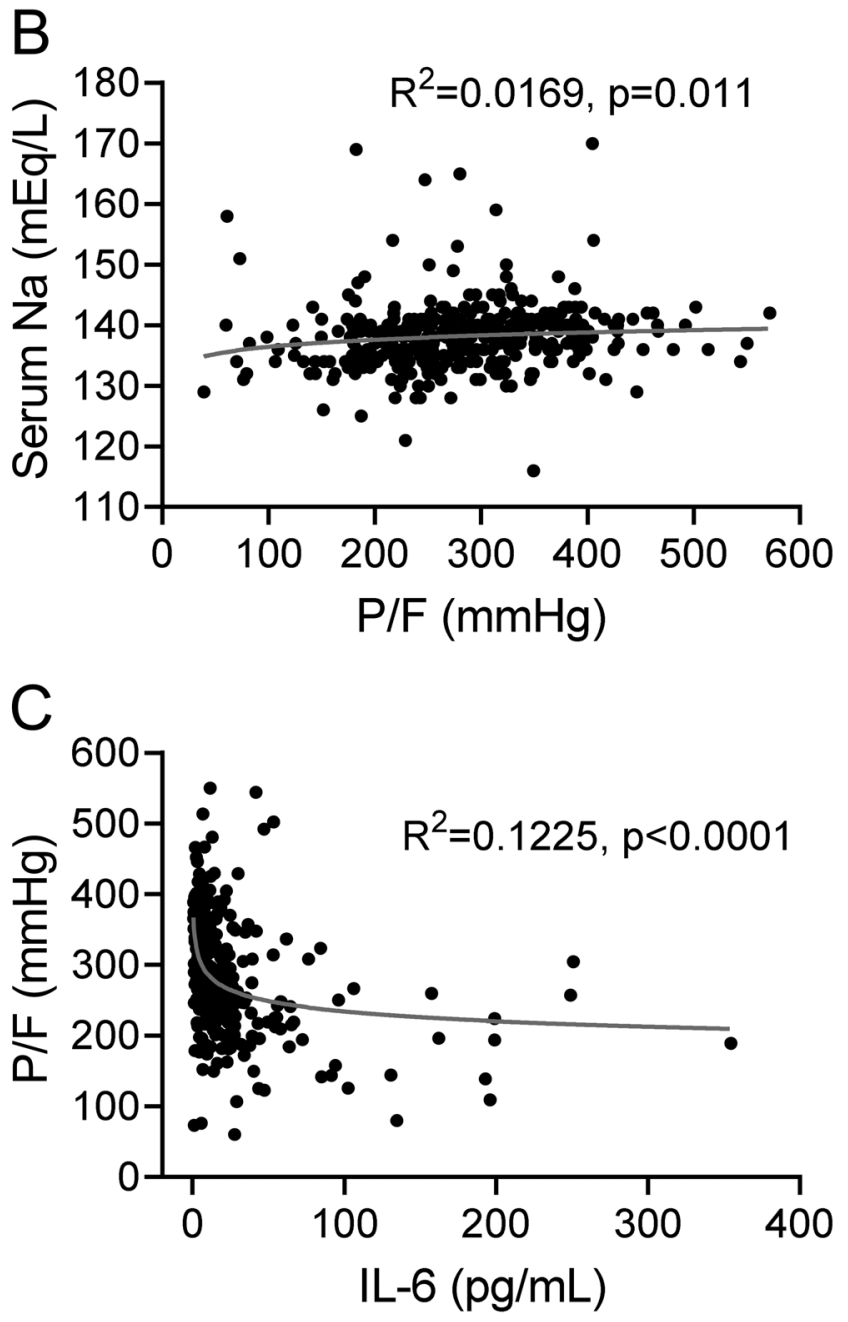

\section{Figure 1}

(A) Best-fitting model for serum $\left[\mathrm{Na}^{+}\right]$variation as a function of IL-6 levels. (B) Best-fitting model for serum [ $\left.\mathrm{Na}^{+}\right]$variation as a function of P/F ratio. (C) Best-fitting model for $\mathrm{P} / \mathrm{F}$ ratio as a function IL-6 levels variation.

\section{Patients' outcome}

The hypoNa group showed a higher prevalence of noninvasive ventilation (NIV) (39\%) and ICU transfer (34\%) compared to normoNa (22\% for both, $P=0.001$ and $P=0.007$, respectively). Only a small percentage of patients with hypernatremia required non-invasive ventilation or ICU admission (i.e. 5\% for both), despite an older age of the patients in this group compared to the other ones (82.2 $\pm 13.1, P=0.001$ vs hypoNa and vs normoNa groups).

After a mean follow-up of $17 \pm 14$ (mean \pm s.D.) days, 45 in-hospital deaths were observed. Of those cases, 23 occurred in normoNa patients, and 19 and 3 in hypoNa and in hyperNa subjects, respectively. Kaplan-Meier curves showed that hypoNa patients had an increased risk of death when compared to normoNa subjects $(P<0.001)$. Conversely, no difference between hyperNa and normoNa patients was observed ( $P=0.224$ ) (Fig. 2 ). Hence, hyperNa patients were excluded from the following analyses.

When serum $\left[\mathrm{Na}^{+}\right]$, IL- 6 and P/F ratio were considered in the same Cox regression model, after adjusting for age and gender, serum $\left[\mathrm{Na}^{+}\right]$and IL-6 maintained a significant association with increased in-hospital mortality $(\mathrm{HR}=1.144(1.006 ; 1.301)$ for each $\mathrm{mEq} / \mathrm{L}$ reduction of serum $\left[\mathrm{Na}^{+}\right]$and $\mathrm{HR}=1.008(1.003 ; 1.013)$ for each $\mathrm{pg} /$ $\mathrm{mL}$ increase of serum IL-6, respectively; both $P<0.05$ ). Conversely no association between the $\mathrm{P} / \mathrm{F}$ ratio and mortality was observed (not shown).

Accordingly, when hyponatremia and elevated IL-6 ( $>10 \mathrm{pg} / \mathrm{mL}$ ) were considered in the same Cox regression model, they resulted in association with 2.7-fold and 10.7fold increased risk of mortality, respectively $(\mathrm{HR}=2.705$ (1.134;6.454), $P=0.025$ and $\mathrm{HR}=10.717$ (1.409;81.517), $P=0.022$ for hyponatremia and elevated IL-6 respectively). 


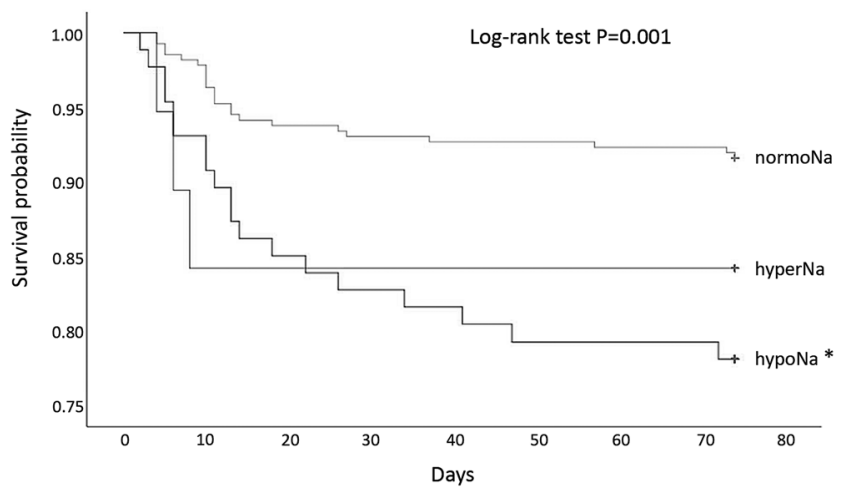

\section{Figure 2}

Kaplan-Meier curves in patients with hyponatremia (hypoNa), normonatremia (normoNa) or hypernatremia (hyperNa) at admission. ${ }^{*} P<0.001$ vs normoNa.

\section{Discussion}

COVID-19 infection has represented a new and unexpected clinical challenge worldwide. Thus, the overall management and pharmacological treatment of affected patients have been somewhat empirical during the first wave of the pandemic earlier in Spring 2020. In such a situation, the observation of clinical signs and laboratory parameters has been an important issue, in order to find possible guidance to identify the most appropriate intervention strategies and early markers of patients' outcome.

Among laboratory indexes, in principle hyponatremia should not be an unexpected finding in COVID-19 patients. Pneumonia, cytokine release, diuretic administration are very well-known etiologies of hyponatremia. In our series of 380 patients, hyponatremia was found in 87 patients (22.9\%) at the time of hospital admission. Hypernatremia was found in 19 patients (5\%) and was associated with more advanced age. This is not surprising if we consider the rather frequent occurrence of dehydration in the elderly (31).

In agreement with our preliminary data on a limited series of patients (12), we confirmed the presence of an inverse correlation between serum $\left[\mathrm{Na}^{+}\right]$and IL-6, whereas a direct correlation between serum $\left[\mathrm{Na}^{+}\right]$and $\mathrm{P} / \mathrm{F}$ ratio was observed. Therefore, hyponatremia appears to be associated with a worse respiratory performance and higher IL-6 levels.

Pro-inflammatory cytokines released by monocytes and macrophages, and particularly IL-6, are able to induce vasopressin secretion via two mechanisms: by a direct non-osmotic stimulation and by damaging alveolar basement membrane, which induces hypoxia, pulmonary vasoconstriction and vasopressin release $(32,33,34$, 35). Hence, in COVID-19, IL-6 could be viewed as the common pathogenic denominator of lung injury and acute respiratory insufficiency on one hand and SIADrelated hyponatremia on the other hand.

Several demographic, clinical and laboratory parameters correlate with prognosis and severity of COVID-19 infection $(36,37)$. Among biochemical markers, lower lymphocyte and platelet counts, increased IL-6 and IL-10 levels, abnormalities in coagulation parameters and in the indexes of liver and kidney function were found to be related to severe disease and unfavorable outcomes (38). More recently, hyponatremia has been suggested as an independent variable for COVID-19 progression to severe disease and death $(25,26,39,40,41)$.

Following our previous brief report (12), we confirmed here in a much larger cohort that hyponatremic COVID19 patients presented a higher risk of ICU transfer, NIV and in-hospital mortality than normonatremic and hypernatremic patients. These findings are also in agreement with data from a recently published multicenter, observational cohort study performed in patients with COVID-19 infection in New York City (42).

Noteworthy, in the present study, we also demonstrated by multivariate analysis that both serum $\left[\mathrm{Na}^{+}\right]$and IL-6 are significantly associated with increased in-hospital mortality independently of age and gender, whereas we did not observe any correlation between $\mathrm{P} / \mathrm{F}$ and the number of deaths. Other studies reported a correlation between P/F and mortality in COVID-19 patients, yet when a cut-off of $200 \mathrm{mmHg}$ was considered $(43,44)$. In addition, we can hypothesize that respiratory failure and lung involvement in COVID-19 patients are just a part of a multiple organ failure. In such a scenario, it is then conceivable that serum $\left[\mathrm{Na}^{+}\right]$and IL- 6 levels, as markers of the cytokine storm induced by SARS-CoV-2 infection, rather than $\mathrm{P} / \mathrm{F}$, may predict a higher risk of in-hospital death. In particular, a 14.4\% (0.6\%-30.1\%) increased risk of death was observed for each $\mathrm{mEq} / \mathrm{L}$ decrease of serum $\left[\mathrm{Na}^{+}\right]$, whereas a $0.8 \%(0.3 \%-1.3)$ increased risk of death was observed for each $\mathrm{pg} / \mathrm{mL}$ increase of serum IL-6. Furthermore, hyponatremia and elevated IL-6 (i.e. $>10$ pg/ $\mathrm{mL}$ ) resulted in a 2.7- and 10.7-fold increased risk of death compared to their normal counterparts, respectively. Of the pro-inflammatory cytokines, IL- 6 exerts a crucial role in the cytokine storm, and it has been described that high levels are a predictor of COVID-19 severity $(45,46)$. However, admittedly serum $\left[\mathrm{Na}^{+}\right]$has the advantage to be readily available by using point-of-care tests. Furthermore, 
it is worth noting that the association between low serum $\left[\mathrm{Na}^{+}\right]$and increased mortality was maintained even after adjustment for IL-6 levels. To our knowledge, this is the first study in which IL-6 was included among possible confounders.

This finding suggests interesting clinical considerations and it could be explained by the fact that SIAD, which is defined as a form of hyponatremia with normal ECF volume, is not the only cause of hyponatremia in COVID19 patients. Although SIAD has been reported as the most frequent etiology of hyponatremia in COVID-19 $(11,47$, 48 ), other conditions can contribute to this electrolyte imbalance, such as vomiting and diarrhea that induce hyponatremia associated with reduced ECF volume (49), or an inadequate dietary intake of sodium. Based on the values of creatinine, BUN and BUN/creatinine that we found in hypoNa patients, we can hypothesize that a subset of these patients were likely to have a reduced ECF volume. On the other hand, the massive release of IL-6 may not be the only determinant of SIAD in SARSCoV-2 affected patients. Human coronaviruses can present neuroinvasive properties, which may lead to inappropriate vasopressin secretion (50). Furthermore, it has been demonstrated that the expression and activity of angiotensin-converting enzyme type 2 (ACE2), which represents the receptor for SARS-CoV-2 on the cell surface, are induced by dietary sodium restriction in rat kidney (51). Since ACE2 is highly expressed also in human proximal tubules, we can hypothesize a role of virusinduced tubular injury in disrupting the function of ion channels, thus contributing to serum $\left[\mathrm{Na}^{+}\right]$alterations.

The strength of our data is reinforced by the fact that in our database serum $\left(\mathrm{Na}^{+}\right)$was corrected for serum glucose, in order to exclude pseudohyponatremia conditions in not well-controlled diabetic patients. This correction is important because it allows a correct definition of different groups (normonatremia, hyponatremia, hypernatremia) and avoids the introduction of errors in the subsequent analyses. In our study, after correcting serum $\left[\mathrm{Na}^{+}\right]$for serum glucose, ten patients were relocated from the hyponatremic into the normonatremic group, whereas one patient was relocated from the normonatremic to the hypernatremic group. Similarly, the correction of $\mathrm{PaO}_{2}$ values for $\mathrm{PaCO}_{2}$ allows not to overestimate the efficiency of pulmonary gas exchange in conditions of hyperventilation. To our knowledge, no other study that addressed serum $\left[\mathrm{Na}^{+}\right]$alterations in COVID-19 patients has considered these potential interfering factors on statistical analyses.
Some limitations should be recognized. Admittedly, in our study, we included only hospitalized individuals, and therefore, our data did not represent all COVID-19 patients. Nevertheless, patients who require hospitalization are in principle those with an increased risk of a more negative outcome. Despite that, serum $\left[\mathrm{Na}^{+}\right]$and IL-6 significantly and independently predicted a worse outcome. In addition, it should be recognized that some correlations between serum $\left[\mathrm{Na}^{+}\right]$and other parameters were relatively weak, although statistically significant. Hence, whether these correlations are clinically meaningful need to be confirmed in larger multicenter studies. With regard to this point, the above mentioned multicenter study performed in patients with COVID-19 infection in New York City supports our findings (42).

In summary, currently available data suggest that the identification of early prognostic markers such as IL-6 and the more readily available serum $\left[\mathrm{Na}^{+}\right]$may be of help in order to timely identify COVID-19 patients with a potential progression to a more severe clinical picture and, consequently, to initiate appropriate therapeutic strategies without any delay. Unfortunately, the COVID19 pandemic is not at the end yet and additional studies should further clarify this issue.

\section{Declaration of interest}

The authors declare that there is no conflict of interest that could be perceived as prejudicing the impartiality of this study.

\section{Funding}

This research did not receive any specific grant from any funding agency in the public, commercial or not-for-profit sector.

\section{Patients' consent}

Written consent has been obtained from each patient/subject or legal representative after a full explanation of the purpose and the nature of all procedures used.

\section{References}

1 Upadhyay A, Jaber BL \& Madias NE. Incidence and prevalence of hyponatremia. American Journal of Medicine 2006119 (Supplement 1) S30-S35. (https://doi.org/10.1016/j.amjmed.2006.05.005)

2 Hoorn EJ, Lindemans J \& Zietse R. Development of severe hyponatremia in hospitalized patients: treatment-related risk factors and inadequate management. Nephrology, Dialysis, Transplantation 200621 70-76. (https://doi.org/10.1093/ndt/gfi082)

3 Cuesta $\mathrm{M} \&$ Thompson CJ. The syndrome of inappropriate antidiuresis (SIAD). Best Practice and Research: Clinical Endocrinology and Metabolism 201630 175-187. (https://doi.org/10.1016/j. beem.2016.02.009) 
4 Swart RM, Hoorn EJ, Betjes MG \& Zietse R. Hyponatremia and inflammation: the emerging role of interleuchin-6 in osmoregulation. Nephron: Physiology 2011118 45-51. (https://doi. org/10.1159/000322238)

5 Benrick A, Schéle E, Pinnock SB, Wernstedt-Asterholm I, Dickson SL, Karlsson-Lindahl L \& Jansson JO. Interleukin-6 gene knockout influences energy balance regulating peptides in the hypothalamic paraventricular and supraoptic nuclei. Journal of Neuroendocrinology 200921 620-628. (https://doi.org/10.1111/j.13652826.2009.01879.x)

6 Dong E, Du H \& Gardner L. An interactive web-based dashboard to track COVID-19 in real time. Lancet: Infectious Diseases 202020 533-534. (https://doi.org/10.1016/S1473-3099(20)30120-1)

7 Cuesta M, Slattery D, Goulden EL, Gupta S, Tatro E, Sherlock M, Tormey W, O'Neill S \& Thompson CJ. Hyponatraemia in patients with community-acquired pneumonia; prevalence and aetiology, and natural history of SIAD. Clinical Endocrinology 201990 744-752. (https://doi.org/10.1111/cen.13937)

8 Leong HN, Chan KP, Oon LL, Koay E, Ng LC, Lee MA, Barkham T, Chen MI, Heng BH, Ling AE et al. Clinical and laboratory findings of SARS in Singapore. Annals of the Academy of Medicine, Singapore 2006 35 332-339. (PMID:16830000)

9 Leong HN, Earnest A, Lim HH, Chin CF, Tan C, Puhaindran ME, Tan A, Chen MI \& Leo YS. SARS in Singapore-predictors of disease severity. Annals of the Academy of Medicine, Singapore 200635 326-331.

10 Choi KW, Chau TN, Tsang O, Tso E, Chiu MC, Tong WL, Lee PO, $\mathrm{Ng} \mathrm{TK}, \mathrm{Ng} \mathrm{WF}$, Lee KC et al. Outcomes and prognostic factors in 267 patients with severe acute respiratory syndrome in Hong Kong. Annals of Internal Medicine 2003139 715-723. (https://doi. org/10.7326/0003-4819-139-9-200311040-00005)

11 Christ-Crain M, Hoorn EJ, Sherlock M, Thompson CJ \& Wass JAH. Endocrinology in the time of COVID-19: management of diabetes insipidus and hyponatraemia. European Journal of Endocrinology 2020 183 G9-G15. (https://doi.org/10.1530/EJE-20-0338)

12 Berni A, Malandrino D, Parenti G, Maggi M, Poggesi L \& Peri A. Hyponatremia, IL-6, and SARS-CoV-2 (COVID-19) infection: may all fit together? Journal of Endocrinological Investigation $2020 \mathbf{4 3}$ 1137-1139. (https://doi.org/10.1007/s40618-020-01301-w)

13 Guan WJ, Ni ZY, Hu Y, Liang WH, Ou CQ, He JX, Liu L, Shan H, Lei CL, Hui DSC et al. Clinical characteristics of coronavirus disease 2019 in China. New England Journal of Medicine 2020382 1708-1720. (https://doi.org/10.1056/NEJMoa2002032)

14 Zhang X, Cai H, Hu J, Lian J, Gu J, Zhang S, Ye C, Lu Y, Jin C, Yu G et al. Epidemiological, clinical characteristics of cases of SARS-CoV-2 infection with abnormal imaging findings. International Journal of Infectious Diseases 202094 81-87. (https://doi.org/10.1016/j. ijid.2020.03.040)

15 Zilberberg MD, Exuzides A, Spalding J, Foreman A, Jones AG, Colby C $\&$ Shorr AF. Hyponatremia and hospital outcomes among patients with pneumonia: a retrospective cohort study. BMC Pulmonary Medicine 20088 16. (https://doi.org/10.1186/1471-2466-8-16)

16 Klein L, O'Connor CM, Leimberger JD, Gattis-Stough W, Pina IL, Felker GM, Adams KF Jr, Califf RM, Gheorghiade M \& OPTIME-CHF Investigators. Lower serum sodium is associated with increased shortterm mortality inhospitalized patients with worsening heart failure: results from the Outcomes of a Prospective Trial of Intravenous Milrinone for Exacerbations of Chronic Heart Failure (OPTIME-CHF) Study. Circulation 2005111 2454-2460. (https://doi.org/10.1161/01. CIR.0000165065.82609.3D)

17 Waikar SS, Mount DB \& Curhan GC. Mortality after hospitalization with mild, moderate, and severe hyponatremia. American Journal of Medicine 2009122 857-865. (https://doi.org/10.1016/j. amjmed.2009.01.027)

18 Kim WR, Biggins SW, Kremers WK, Wiesner RH, Kamath PS, Benson JT, Edwards E \& Therneau TM. Hyponatremia and mortality among patients on the liver-transplant waiting list. New England Journal of Medicine 2008359 1018-1026. (https://doi.org/10.1056/ NEJMoa0801209)

19 Schutza FAB, Xiea W, Donskovb F, Sircarc M, McDermottd DF, Rinie BI, Agarwal N, Kumar Pal SK, Srinivas S, Kollmannsberger C et al. The impact of low serum sodium on treatment outcome of targeted therapy in metastatic renal cell carcinoma: results from the International Metastatic Renal Cell Cancer Database Consortium. European Urology 201465 723-730. (https://doi.org/10.1016/j. eururo.2013.10.013)

20 Berardi R, Caramanti M, Fiordoliva I, Morgese F, Savini A, Rinaldi S, Torniai M, Tiberi M, Ferrini C, Castagnani M et al. Hyponatraemia is a predictor of clinical outcome for malignant pleural mesothelioma. Supportive Care in Cancer 201523 621-626. (https://doi.org/10.1007/ s00520-014-2398-6)

21 Terzian C, Frye EB \& Piotrowski ZH. Admission hyponatremia in the elderly: factors influencing prognosis. Journal of General Internal Medicine 19949 89-91. (https://doi.org/10.1007/BF02600208)

22 Stelfox HT, Ahmed SB, Khandwala F, Zygun D, Shahpori R \& Laupland $\mathrm{K}$. The epidemiology of intensive care unit-acquired hyponatremia and hypernatraemiain medical-surgical intensive care units. Critical Care 200812 R162. (https://doi.org/10.1186/cc7162)

23 Corona G, Giuliani C, Parenti G, Norello D, Verbalis JG, Forti G, Maggi M \& Peri A. Moderate hyponatremia is associated with increased risk of mortality: evidence from a meta-analysis. PLOS ONE 20138 e80451. (https://doi.org/10.1371/journal.pone.0080451)

24 Marroncini G, Fibbi B, Errico A, Grappone C, Maggi M \& Peri A. Effects of low extracellular sodium on proliferation and invasive activity of cancer cells in vitro. Endocrine 202067 473-484. (https:// doi.org/10.1007/s12020-019-02135-0)

25 Duan J, Wang X, Chi J, Chen H, Bai L, Hu Q, Han X, Hu W, Zhu L, Wang X et al. Correlation between the variables collected at admission and progression to severe cases during hospitalization among patients with COVID-19 in Chongqing. Journal of Medical Virology 202092 2616-2622. (https://doi.org/10.1002/jmv.26082)

26 Lippi G, South AM \& Henry BM. Electrolyte imbalances in patients with severe coronavirus disease 2019 (COVID-19). Annals of Clinical Biochemistry 202057 262-265. (https://doi. org/10.1177/0004563220922255)

27 Park M, Cook AR, Lim JT, Sun Y \& Dickens BL. A systematic review of COVID-19 epidemiology based on current evidence. Journal of Clinical Medicine 20209 967-979. (https://doi.org/10.3390/ jcm9040967)

28 Luo P, Liu Y, Qiu L, Liu X, Liu D \& Li J. Tocilizumab treatment in COVID-19: a single center experience. Journal of Medical Virology 202092 814-818. (https://doi.org/10.1002/jmv.25801)

29 Hodax JK, Balo SR \& Yalcindag A. SIADH in sysyetmic JIA resolving after treatment with an IL-6 inhibitor. Pediatrics 2018141 e20164174. (https://doi.org/10.1542/peds.2016-4174)

30 Bernard GR, Artigas A, Brigham KL, Carlet J, Falke K, Hudson L, Lamy M, Legall JR, Morris A \& Spragg R. The American-European consensus conference on ARDS. Definitions, mechanisms, relevant outcomes, and clinical trial coordination. American Journal of Respiratory and Critical Care Medicine 1994149 818-824. (https://doi. org/10.1164/ajrccm.149.3.7509706)

31 Bagshaw SM, Townsend DR \& McDermid RC. Disorders of sodium and water balance in hospitalized patients. Journal of Anesthesia 2009 5 151-167. (https://doi.org/10.1007/s12630-008-9017-2)

32 Mehta P, McAuley DF, Brown M, Sanchez E, Tattersall RS, Manson JJ \& HLH Across Speciality Collaboration, UK. COVID19: consider cytokine storm syndromes and immunosuppression. Lancet 2020395 1033-1034. (https://doi.org/10.1016/S01406736(20)30628-0)

33 Park SJ \& Shin JI. Inflammation and hyponatremia: an underrecognized condition? Korean Journal of Pediatrics 201356 519-522. (https://doi.org/10.3345/kjp.2013.56.12.519) 
34 Qin C, Zhou L, Hu Z, Zhang S, Yang S, Tao Y, Xie C, Ma K, Shang K, Wang $\mathrm{W}$ et al. Dysregulation of immune response in patients with COVID-19 in Wuhan, China. Clinical Infectious Diseases 202071 762-768. (https://doi.org/10.1093/cid/ciaa248)

35 Mastorakos G, Weber JS, Magiakou MA, Gunn H \& Chrousos GP. Hypothalamic-pituitary-adrenal axis activation and stimulation of systemic vasopressin secretion by recombinant interleukin-6 in humans: potential implications for the syndrome of inappropriate vasopressin secretion. Journal of Clinical Endocrinology and Metabolism 199479 934-939. (https://doi.org/10.1210/jcem.79.4.7962300)

36 Hu Y, Sun J, Dai Z, Deng H, Li X, Huang Q, Wu Y, Sun L \& Xu Y. Prevalence and severity of corona virus disease 2019 (COVID-19): a systematic review and meta-analysis. Journal of Clinical Virology 2020 127 104371. (https://doi.org/10.1016/j.jcv.2020.104371)

37 Corona G, Pizzocaro A, Vena W, Rastrelli G, Semeraro F, Isidori AM, Pivonello R, Salonia A, Sforza A \& Maggi M. Diabetes is most important cause for mortality in COVID-19 hospitalized patients: systematic review and meta-analysis. Reviews in Endocrine and Metabolic Disorders 202122 275-296. (https://doi.org/10.1007/ s11154-021-09630-8)

38 Henry BM, de Oliveira MHS, Benoit S, Plebani M \& Lippi G. Hematologic, biochemical and immune biomarker abnormalities associated with severe illness and mortality in coronavirus disease 2019 (COVID-19): a meta-analysis. Clinical Chemistry and Laboratory Medicine 202058 1021-1028. (https://doi.org/10.1515/cclm-20200369)

39 Tezcan ME, Dogan Gokce G, Sen N, Zorlutuna Kaymak N \& Ozer RS. Baseline electrolyte abnormalities would be related to poor prognosis in hospitalized coronavirus disease 2019 patients. New Microbes and New Infections 202037 100753. (https://doi.org/10.1016/j. nmni.2020.100753)

$40 \mathrm{Wu}$ Y, Hou B, Liu J, Chen Y \& Zhong P. Risk factors associated with long-term hospitalization in patients with COVID-19: a singlecentered, retrospective study. Frontiers in Medicine 20207315. (https://doi.org/10.3389/fmed.2020.00315)

$41 \mathrm{Hu}$ W, Lv X, Li C, Xu Y, Qi Y, Zhang Z, Li M, Cai F, Liu D, Yue J et al. Disorders of sodium balance and its clinical implications in COVID19 patients: a multicenter retrospective study. Internal and Emergency Medicine 2020 In press. (https://doi.org/10.1007/s11739-020-02515-9)

42 Frontera JA, Valdes E, Huang J, Lewis A, Lord AS, Zhou T, Kahn DE, Melmed K, Czeisler BM, Yaghi S et al. Prevalence and impact of hyponatremia in patients with coronavirus disease 2019 in New York City. Critical Care Medicine 202048 e1211-e1217. (https://doi org/10.1097/CCM.0000000000004605)
43 Santus P, Radovanovic D, Saderi L, Marino P, Cogliati C, De Filippis G, Rizzi M, Franceschi E, Pini S, Giuliani F et al. Severity of respiratory failure at admission and in-hospital mortality in patients with COVID-19: a prospective observational multicentre study. BMJ Open 202010 e043651. (https://doi.org/10.1136/ bmjopen-2020-043651)

44 Zahid U, Ramachandran P, Spitalewitz S, Alasadi L, Chakraborti A, Azhar M, Mikhalina G, Sherazi A, Narh JT, Khattar P et al. Acute kidney injury in COVID-19 patients: an inner City Hospital experience and policy implications. American Journal of Nephrology 202051 786-796. (https://doi.org/10.1159/000511160)

45 Diao B, Wang C, Tan Y, Chen X, Liu Y, Ning L, Chen L, Li M, Liu Y, Wang G et al. Reduction and functional exhaustion of $\mathrm{T}$ cells in patients with coronavirus disease 2019 (COVID-19). Frontiers in Immunology 202011 827. (https://doi.org/10.3389/ fimmu.2020.00827)

46 Han H, Ma Q, Li C, Liu R, Zhao L, Wang W, Zhang P, Liu X, Gao G, Liu F et al. Profiling serum cytokines in COVID-19 patients reveals IL-6 and IL-10 are disease severity predictors. Emerging Microbes and Infections 20209 1123-1130. (https://doi.org/10.1080/22221751.202 $0.1770129)$

47 Yousaf Z, Al-Shokri SD, Al-soub H \& Mohamed MFH. Covid-19 associated SIADH; a clue in the times of pandemic! American Journal of Physiology: Endocrinology and Metabolism 2020318 E882-E885. (https://doi.org/10.1152/ajpendo.00178.2020)

48 Ata F, Almasri H, Sajid J \& Yousaf Z. COVID-19 presenting with diarrhoea and hyponatraemia. BMJ Case Reports 202013 e235456. (https://doi.org/10.1136/bcr-2020-235456)

49 Sbardella E, Isidori AM, Arnaldi G, Arosio M, Barone C, Benso A, Berardi R, Capasso G, Caprio M, Ceccato F et al. Approach to hyponatremia according to the clinical setting: consensus statement from the Italian Society of Endocrinology (SIE), Italian Society of Nephrology (SIN), and Italian Association of Medical Oncology (AIOM). Journal of Endocrinological Investigation 20184 3-19. (https:// doi.org/10.1007/s40618-017-0776-x)

$50 \mathrm{Gu}$ J, Gong E, Zhang B, Zheng J, Gao Z, Zhong Y, Zou W, Zhan J, Wang S, Xie Z et al. Multiple organ infection and the pathogenesis of SARS. Journal of Experimental Medicine 2005202 415-424. (https:// doi.org/10.1084/jem.20050828)

51 Hamming I, van Goor H, Turner AJ, Rushworth CA, Michaud AA, Corvol P \& Navis G. Differential regulation of renal angiotensinconverting enzyme (ACE) and ACE2 during ACE inhibition and dietary sodium restriction in healthy rats. Experimental Physiology 200893 631-638. (https://doi.org/10.1113/expphysiol.2007.041855)

Received 17 December 2020

Revised version received 8 April 2021

Accepted 5 May 2021 